This document is the unedited Author's version of a Submitted Work that was subsequently accepted for publication in 'Environmental Science \& Technology', copyright @ American Chemical Society after peer review. To access the final edited and published work: https://www.sciencedirect.com/science/article/pii/S0045653514008728

\title{
Photochemical reactions of divalent mercury with thioglycolic acid: Formation of mercuric sulfide particles
}

\author{
Lin Si, Parisa A. Ariya
}

\begin{abstract}
Mercury ( $\mathrm{Hg}$ ) is a key toxic global pollutant. Studies in aquatic environment have suggested that thiols could be important for mercury speciation. Thioglycolic acid has been detected in various natural water systems and used as a model compound to study the complicated interaction between mercury and poly- functional dissolved organic matter (DOM). We herein presented the first evidence for mercury particle formation during kinetic and product studies on the photochemistry of divalent mercury $\left(\mathrm{Hg}^{2+}\right)$ with thioglycolic acid at near environmental conditions. Mercuric sulfide (HgS) particles formed upon photolysis were identified by high-resolution transmission electron microscopy coupled with energy dispersive spectrometry and select area electron diffraction. Kinetic data were obtained using UV-visible spectro- photometry and cold vapour atomic fluorescent spectrometry. The apparent first-order reaction rate con- stant under our experimental conditions was calculated to be $(2.3 \pm 0.4) \times 10^{-5} \mathrm{~s}^{-1}$ at $T=296 \pm 2 \mathrm{~K}$ and $\mathrm{pH}$ 4.0. It was found that $(89 \pm 3) \%$ of the reactants undergo photoreduction to generate elemental mer- cury $\left(\mathrm{Hg}^{0}\right)$. The effects of ionic strengths, $\mathrm{pH}$ and potassium ion were also investigated. The formation of $\mathrm{HgS}$ particles pointed to the possible involvement of heterogeneous processes. Our kinetic results indi- cated the importance of weak binding sites on DOM to $\mathrm{Hg}$ in photoreduction of $\mathrm{Hg}^{2+}$ to $\mathrm{Hg}^{0}$. The potential implications of our data on environmental mercury transformation were discussed.
\end{abstract}

\section{Introduction}

Mercury contamination in the environment is a global problem because it can travel long distances in the atmosphere to reach remote locations. Mercury $(\mathrm{Hg})$ is a known neurotoxin that accumulates in aquatic food chain and can pose health threats to hu mans and wildlife through consumption of contaminated fish (Lanzillotta and Ferrara, 2001; O'Driscoll et al., 2003). Photochemical reactions of $\mathrm{Hg}$-containing species may be homogeneous or heterogeneous in the environment (Nriagu, 1994) and accurate implementation of their chemical parameters is essential for realistic modeling of mercury cycling (Subir et al., 2011). Several studies on photolysis of $\mathrm{Hg}^{2+}$-organic ligands complexes have emphasized the importance of organic ligands on photochemical reduction of $\mathrm{Hg}^{2+}$ in natural waters (Kunkely et al., 1997; Zhang and Lindberg, 2001; Gardfeldt and Jonsson, 2003). Due to the different stability and reactivity of various $\mathrm{Hg}^{2+}$-organic ligand complexes, the mechanism and kinetics of photochemical reactions of $\mathrm{Hg}$ could vary dramatically (Si and Ariya, 2008, 2011).

Compounds with sulfhydryl (thiol) groups (-SH) are known to be strong complexing ligands for soft, B-type metals like $\mathrm{Hg}$ (Krezel and Bal, 1999). Various low-molecular-mass (LMM) thiols such as thioglycolic acid (TGA), cysteine and glutathione, have been detected at nanomolar to millimolar levels in seawater (Matrai and Vetter, 1988; Tang et al., 2000; Al-Farawati and van den Berg, 2001) and freshwater systems (Zhang et al., 2004; Dryden et al., 2007). Direct spectroscopic evidence for the complexation of $\mathrm{Hg}$ (II) with cysteine (Jalilehvand et al., 2006), penicillamine (Leung et al., 2007) and glutathione (Mah and Jalilehvand, 2008) has been provided in alkaline aqueous solutions. In these studies, Hg-thiol complexes with the coordination numbers of 2-4 are formed when thiol/ $\mathrm{Hg}^{2+}$ molar ratio $>2$. However, there is little information on the photochemical reaction between these LMM thiol compounds and oxidized mercury species.

Dissolved organic matter (DOM) interacts very strongly with mercury via complexation and photochemical reactions (Rivichandran, 2004). Thiol groups on DOM are important in con- trolling the speciation and mobility of mercury in aqueous and soil environments (Smith et al., 2002). Experimental data supported the hypothesis that the bonding of mercury by soil organic matter involved one reduced S group and one oxygen-containing functional group such as carboxylic or phenolic group (Skyllberg et al., 2000). It has also been pointed out that $\mathrm{Hg}^{2+}$ may form mixed complexes with one thiol and one other ligand (e.g., carboxyl) on DOM in natural environment (Dong et al., 2011). Because of their simple, identifiable structure, lowmolecular-weight organic com- pounds are usually used as surrogates for different functional groups of natural DOM in terms of their interaction with $\mathrm{Hg}^{2+}$ (Zheng and Hintelmann, 2010). Thioglycolic acid has been used as a model ligand to study the dissolution of cinnabar by DOM (Rivichandran et al., 1998), precipitation and aggregation of metacinnbar by DOM (Ravichandran et al., 1999) and growth of mercuric sulfide (HgS) nanoparticles in DOM-containing water (Deonarine and HsuKim, 2009). These studies showed that the binding of $\mathrm{Hg}^{2+}$ to either TGA or DOM seems to disintegrate and stabilize small units of $\mathrm{HgS}(\mathrm{s})$ in a seemingly similar way.

The objective of this research was to provide the first detailed kinetic and product study on the photochemical reaction of oxidized mercury species with thioglycolic acid. During the course of these studies, we provided the first experimental evidence for formation of $\mathrm{HgS}$ particles and possible involvement of heterogeneous processes.

\section{Materials and methods}

The formation of particles upon photolysis were identified by high-resolution transmission electron microscopy (HR-TEM) coupled with energy dispersive spectrometry (EDS) and select area electron diffraction (SAED). The rate constants were obtained using UV-visible (UV-vis) spectrophotometry and cold vapour atomic fluorescent spectrometry (CVAFS). The effects of ionic strengths, $\mathrm{pH}$ and potassium ion were also investigated using UV-vis spectrophotometry. Details on preparation of solutions used were described in the appendix. The reaction mixture contained aqueous $\mathrm{Hg}^{2+}$ and $\mathrm{TGA}\left(\mathrm{HSCH}_{2} \mathrm{COOH}\right)$ solutions at $\mathrm{Hg}^{2+} /$ TGA molar ratio of 1.1 except for determination of the branching ratio. At this molar ratio, the complex formed is believed 
This document is the unedited Author's version of a Submitted Work that was subsequently accepted for publication in 'Environmental Science \& Technology', copyright @ American Chemical Society after peer review. To access the final edited and published work: https://www.sciencedirect.com/science/article/pii/S0045653514008728

to be $\mathrm{Hg}\left(\mathrm{OOCCH}_{2} \mathrm{~S}\right)$ complex (Martell et al., 1998). This molar ratio was chosen as a model to represent mixed complexes of $\mathrm{Hg}^{2+}$ with one strong (e.g. - $\mathrm{SH}$ ) and one weak (e.g. - $\mathrm{COOH}$ ) binding sites on DOM. Dissolved oxy- gen was removed from Mill-Q water used and

all the samples by purging with UHP Argon gas via Teflon tubing for at least $20 \mathrm{~min}$. The experiments were carried out in Pyrex vessels equipped with Telfon-coated magnetic stirrers to ensure homogeneous mixing. The reaction vessels were immediately closed after purging with UHP Ar gas for at least $20 \mathrm{~min}$. and remained gas-tight until after the measurement was done. The irradiation sources were 4 Luz-chem UV lamps ( $300 \mathrm{~nm} \leq \lambda \leq 400 \mathrm{~nm}$ ) positioned vertically on the sides of the box and each lamp was $18 \mathrm{~cm}$ away from the reaction vessels. Lamp spectra was provided in the appendix, Fig. A1. Dark control experiments were performed by keeping the reaction mixtures in an optically-closed box. All the experiments were carried out with an initial $\mathrm{pH}$ of 4.0 except for $\mathrm{pH}$ variation experiments.

\subsection{Formation of particles}

It was observed that dark-coloured particles were formed upon photolysis of the reaction mixture. The formed particles were collected after 24-h UV photolysis at the initial $\mathrm{Hg}\left(\mathrm{OOCCH}_{2} \mathrm{~S}\right)$ concentrations $\left(\left[\mathrm{Hg}\left(\mathrm{OOCCH}_{2} \mathrm{~S}\right)\right]_{0}\right)$ of $2.5 \times 10^{-10} \mathrm{M}$ and $3.5 \times 10^{-5} \mathrm{M}$ for analysis. The collected particles were suspended in deoxygenated Milli $\mathrm{Q}$ water, and a small aliquot of the suspension was placed on a $\mathrm{Cu}$ grid for transmission electron microscopy (TEM) and allowed to dry. The TEM grids were analyzed using a high resolution transmission electron microscope (JEOL 2000 FXTEM). The elemental composition was obtained by energy dispersive spectroscopy (EDS; JEOL2000). Select area electron diffraction (SAED) was performed to study the crystal structure of these particles.

\subsection{Kinetic studies}

\subsubsection{Determination of reaction rate constants using $U V$-vis spectrophotometry}

UV-vis spectra were acquired with a Varian Cary-50-Bio spectrophotometer at $1 \mathrm{~nm}$ resolution and a scan speed of $300 \mathrm{~nm} \mathrm{~min}^{-1}$. The changes of the concentration of $\mathrm{Hg}\left(\mathrm{OOCCH}_{2} \mathrm{~S}\right)$ was followed by recording changes in absorption intensity at $235 \mathrm{~nm}$ with time, at $\left[\mathrm{Hg}\left(\mathrm{OOCCH}_{2} \mathrm{~S}\right)\right]_{0}$ of $16-43 \mu \mathrm{M}, \mathrm{pH} 4.0$ and

$T=296 \pm 2 \mathrm{~K}$. The rate constant of the photochemical reaction of $\mathrm{Hg}^{2+}$ by TGA was obtained by fitting the data into Eq. A9. A quartz cell with the path length of $1 \mathrm{~cm}$ was used for all the measurements except for kinetic studies performed for the initial concentration of TGA at $16 \mu \mathrm{M}$ where a quartz cell with the path length 0 $10 \mathrm{~cm}$ was utilized. At time intervals, a $3 \mathrm{~mL}$ sample was removed by syringe from the bulk solution and its absorbance was measured using UV-vis spectrometry after filtration $(0.45 \mu \mathrm{m})$. The remaining solution was purged with UHP argon for at least $20 \mathrm{~min}$. to remove volatile $\mathrm{Hg}(0)$ formed during irradiation. A slight variation of $\mathrm{pH}( \pm 0.2)$ was observed during the course of experiments. The effects of ionic strengths and $\mathrm{pH}$ on the reaction rate were investigated. The ionic strengths of the solutions were varied from $10^{-3} \mathrm{M}$ to $0.1 \mathrm{M}$ by adding various amounts of sodium perchlorate into the reaction mixture. $\mathrm{pH}$ was adjusted by firstly acidifying the solution mixture to $\mathrm{pH} 2.0 \mathrm{using}$ $1 \% \mathrm{HClO}_{4}$ solution and then adding aliquots of dilute $\mathrm{NaOH}$ solution. $\mathrm{pH}$ was measured using a Corning $430 \mathrm{pH}$ meter. The effect of $\mathrm{K}^{+}$on the rate constant was evaluated by substituting sodium perchlorate with equal moles of potassium perchlorate at $I=0.02 \mathrm{M}$.

\subsubsection{Determination of the branching ratio using UV-vis spectrophotometry}

The branching ratio of the photolysis of $\mathrm{Hg}^{2+}$-TGA complex was determined as the ratio of the amount of $\mathrm{Hg}^{0}$ produced to the initial amount of $\mathrm{Hg}\left(\mathrm{OOCCH}_{2} \mathrm{~S}\right)$ complex $(16-43 \mu \mathrm{M})$. To determine the amount of $\mathrm{Hg}^{0}$ produced during photochemical reaction, the reaction mixture at $\mathrm{Hg}^{2+} / \mathrm{TGA}$ molar ratio of 10 was irradiated for $72 \mathrm{~h}$. At this molar ratio, $\mathrm{Hg}^{0}$ formed during the reaction was trapped as $\mathrm{Hg}^{2+}$, whose concentration was calculated from its absorbance at $236 \mathrm{~nm}_{\mathbf{z}}$ (van Loon et al., 2000).

\subsubsection{Determination of reaction rate constants using CVAFS}

The production of elemental mercury $\left(\mathrm{Hg}^{0}\right)$ at time intervals was monitored using a cold vapour atomic fluorescent spectrometer (CVAFS) (Tekran 2600). The blank was the solution containing only mercuric nitrate. Experiments were conducted at $\left[\mathrm{Hg}\left(\mathrm{OOCCH}_{2} \mathrm{~S}\right)\right]_{0}$ of $25-360 \mathrm{pM}$. Method details and experimental setup were previously described by Si and Ariya (2011). Apparent rate constants were obtained by fitting the kinetic data to the following equation:

$$
-\ln \left(1-\frac{\left[\mathrm{Hg}^{0}\right]_{t}}{\left.0.89 \times\left[\mathrm{Hg} \mathrm{OOCCH} \mathrm{H}_{2} \mathrm{~S}\right)\right]_{0}}\right)=k t
$$

where $t, k$ and $\mathrm{Hg}^{0}{ }_{t}$ represented the reaction time, the overall rate constant and the concentration of $\mathrm{Hg}^{0}$ at the reaction time $t$, respectively.

Detailed theoretical explanation on kinetic studies was provided in the appendix.

\subsection{Chemicals and materials}


This document is the unedited Author's version of a Submitted Work that was subsequently accepted for publication in 'Environmental Science \& Technology', copyright @ American Chemical Society after peer review. To access the final edited and published work: https://www.sciencedirect.com/science/article/pii/S0045653514008728

Mercuric Nitrate $(98+\%)$, nitric acid (Trace metal grade) and ACS-grade sodium perchlorate, sodium hydroxide, potassium per- chlorate and perchloric acid (60\%) were supplied by Fisher Scientific. Mercuric oxide (red, 99.999\%) and thioglycolic acid $(99+\%)$ were purchased from Sigma-Aldrich. The ultra high purity (UHP) argon (certified oxygen content $<5$ ppmv) was obtained from BOC Canada. All solutions were prepared in Milli-Q water $(18.2 \mathrm{MX} \mathrm{cm})$

\section{Results and discussion}

\subsection{Formation of $\mathrm{HgS}$ particles}

Some dark-coloured particles was formed upon UV irradiation of the reaction mixture. These solid products were identified as submicron, crystalline $\mathrm{HgS}$ particles by HR-TEM coupled with EDS and SAED. Fig. 1(a) showed a typical grain area of TEM bright field images of the collected black particles. The corresponding EDS spectrum of the grain was illustrated in Fig. 1(b), which was dominated by mercury and sulfur peaks with copper peaks caused by the grid. The EDS analysis indicated a mercury-sulfur association in these particles which was consistent with the presence of $\mathrm{HgS}$ (Hyland et al., 1990; Huerta-Diaz and Morse, 1992). The particles were further analyzed by TEM with SAED (Fig. 1(c)) to confirm the presence
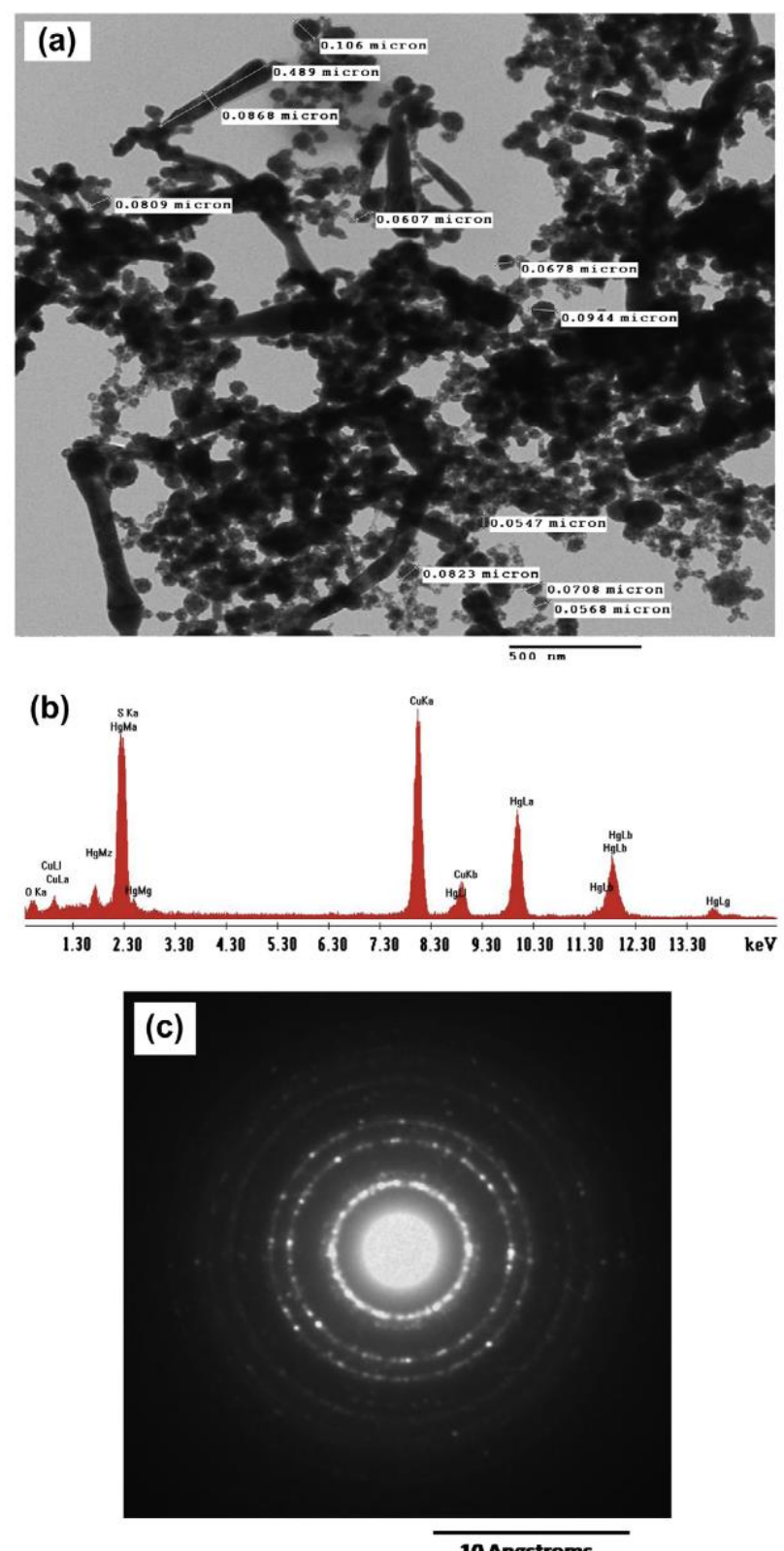

10 Angstroms

Fig. 1. (a) HR-TEM bright field image of HgS grain; (b) EDS spectrum of HgS formation and (c) SAED pattern of HgS grain. 
This document is the unedited Author's version of a Submitted Work that was subsequently accepted for publication in 'Environmental Science \& Technology', copyright @ American Chemical Society after peer review. To access the final edited and published work: https://www.sciencedirect.com/science/article/pii/S0045653514008728

of crystalline metacinnabar. The multiple points on the diffraction rings indicated that the grain areas were made up of many individual grains, and the presence of diffuse rings also indicates some less crystalline $\mathrm{HgS}$. Our results quantitatively matched formerly-reported diffraction patterns of $\mathrm{HgS}$ particles (Barnett et al., 1998), which confirmed $\mathrm{HgS}_{(\mathrm{s})}$ as one of the reaction products. Previous studies showed that Pyrex-filtered ultraviolet light $(\mathrm{k}>290 \mathrm{~nm})$ decomposed the methylmercury-thiol complexes $\left(\mathrm{H}_{3} \mathrm{C}-\mathrm{Hg}-\mathrm{SR}\right)$ with cleavage of the $\mathrm{C}-\mathrm{Hg}$ bond to form inorganic mercury precipitate (Baughman et al., 1973). Similarly, we could speculate that $\mathrm{HgS}$ may be formed via cleavage of the relatively weak $\mathrm{O}-\mathrm{Hg}$ bond on $\mathrm{Hg}\left(\mathrm{OOCCH}_{2} \mathrm{~S}\right)$ complex. Further studies are needed to elucidate the detailed reaction mechanism.

To our knowledge, this is the first time that the formation of $\mathrm{HgS}$ particles was identified during the photochemical reaction of $\mathrm{Hg}^{2+}$ with thioglycolic acid in aqueous phase. In the atmosphere, $\mathrm{HgS}$ has been suggested to be an important $\mathrm{Hg}$ species occurring in airborne particulate matter/aerosols (Munthe et al., 2001; Feng et al., 2004). Nanoparticulate or colloidal HgS particles have been reported to exist in nature (Barnett et al., 1998; Lowry et al., 2004). Recent studies using synthesized $\mathrm{HgS}$ nanoparticles at $\mathrm{nM}$ level indicated that these nanoparticles may be an important source of bioavailable mercury for methylating bacteria (Zhang et al., 2012). The observation of formation of $\mathrm{HgS}$ particles during photolysis of the $\mathrm{Hg}^{2+}-\mathrm{TGA}^{2}$ system was novel, since these particles may cause heterogeneous reactions to occur. $\mathrm{HgS}$ has been reported to be a direct-bandgap semiconductor with band gap energy in the region of 2.09-2.1 eV at $300 \mathrm{~K}$ (Pal et al., 2003). Experimental evidence suggested that $\mathrm{Hg}^{2+}$ seemed to have under- gone in-situ reductive deposition on $\mathrm{HgS}$ as $\mathrm{Hg}^{0}$ during the photoirradiation ( $\mathrm{k}>300$ $\mathrm{nm}$ ) (Pal et al., 2003). Recent modelling studies illustrated the importance of heterogeneous chemistry on aerosol surfaces such as $\mathrm{HgS}_{(\mathrm{p})}$ in conversions between $\mathrm{Hg}^{0}$ and $\mathrm{Hg}^{2+}$ in the atmosphere (Karamchandani et al., 2012). The role of this possible heterogeneous process in photochemistry of $\mathrm{Hg}^{2+}$ with organic acids requires further evaluation. The evidence for such heterogeneous reactions should be further investigated in other environmental matrices including sediments and soils, which have rarely been investigated (Deonarine and Hsu-Kim, 2009)

\subsection{Kinetic studies}

\subsubsection{UV-vis spectroscopy}

The complexation reaction between $\mathrm{Hg}^{2+}$ and TGA under our experimental conditions can be expressed as follows.

$$
\mathrm{Hg}^{2+}+\mathrm{HOOCCH}_{2} \mathrm{SH} \rightarrow \rightarrow \mathrm{Hg}\left(\mathrm{OOCCH}_{2} \mathrm{~S}\right)+2 \mathrm{H}^{+}
$$

$\mathrm{Hg}^{2+}$ was expected to bind in a twofold coordination with one carboxylic group and one thiol group (Skyllberg et al., 2000). The stability constant of this $\mathrm{Hg}^{2+}$-TGA complex at $T=298 \mathrm{~K}$ and $I=0.1 \mathrm{M}$ (the symbol " $I$ " represents the ionic strength herein and after), is $3.210^{34}$ (Martell et al., 1998). However, its UV-vis spectrum has not been characterized. A spectrum was recorded immediately following the addition of TGA to a solution of $300 \mu \mathrm{MM} \mathrm{Hg} \mathrm{Hg}^{2+} \mathrm{at} T=296 \mathrm{~K}$ and $I=0.1 \mathrm{M}$. Two broad absorption shoulders at around $195 \mathrm{~nm}$ and $235 \mathrm{~nm}$, were observed in the UV-vis spectrum of $\mathrm{Hg}\left(\mathrm{OOCCH}_{2} \mathrm{~S}\right)$ complex. Its absorption intensity varied linearly with $\left[\mathrm{Hg}\left(\mathrm{OOCCH}_{2} \mathrm{~S}\right)\right]_{0}$ in the range of $5-60 \mu \mathrm{M}$. According to Beer's Law, the variation of molar absorptivity of this $\mathrm{Hg}^{2+}-\mathrm{TGA}^{2}$ complex with the wavelength was plotted as shown in Fig. A2. This demonstrated that $\mathrm{Hg}\left(\mathrm{OOCCH}_{2} \mathrm{~S}\right)$ substantially absorbs photons from the UV region of the natural sunlight $(2906 \mathrm{k} 6400 \mathrm{~nm})$. Photolysis of the reaction mixture for $24 \mathrm{~h}$ using UV lamps resulted in a decrease of $88 \%$ in absorbance at $235 \mathrm{~nm}$, whereas little change $( \pm 10 \%)$ in UV-vis spectra was observed for dark control experiments. Our results indicated that UV light played a role in initiating the photochemical reactions between oxidized mercury species and thioglycolic acid.

The time-evolution of the concentration of $\mathrm{Hg}\left(\mathrm{OOCCH}_{2} \mathrm{~S}\right)$ could be described by a single-exponential function, characteristic of an apparent first-order reaction (Fig. 2(a)). The apparent first-order rate constant was independent of $\left[\mathrm{Hg}\left(\mathrm{OOCCH}_{2} \mathrm{~S}\right)\right]_{0}$. The rate constant was invariant with ionic strength in the range of $0.001-0.1 \mathrm{M}$. The lack of a significant ionic strength effect on the rate reflected the absence of charge separation in the rate-deter- mining step, which supported our assumption that the photo- chemical reaction between $\mathrm{Hg}^{2+}$ and TGA was probably mediated by the neutral $\mathrm{Hg}\left(\mathrm{OOCCH}_{2} \mathrm{~S}\right)$ complex. The measured rate constants under various experimental conditions were summarized in Table 1. Thus the rate law is apparently first-order with the rate constant of $(2.4 \pm 0.4) 10^{-5} \mathrm{~s}^{-1}$ at $T=296 \mathrm{~K}$, $\mathrm{pH}$ 4.0. The apparent rate law at $\mathrm{pH} 4.0$ is therefore

$$
\frac{-d\left[\mathrm{Hg}\left(\mathrm{OOCCH}_{2} \mathrm{~S}\right)\right]}{d t}=k \cdot\left[\mathrm{Hg}\left(\mathrm{OOCCH}_{2} \mathrm{~S}\right)\right]
$$

The obtained apparent rate constant was in the same order of magnitude as that of the photochemical reduction of $\mathrm{Hg}^{2+}$ by cysteine (1.3× $10^{-5} \mathrm{~s}^{-1}$ at $\left.T=293-295 \mathrm{~K}, \mathrm{pH} 3.6\right)$ (Zheng and Hintelmann, 2010). Compared with our previous studies on photo- reduction of $\mathrm{Hg}^{2+}$ by alkanethiols ( $\mathrm{Si}$ and Ariya, 2011), substitution of one strong binding site (-SH) with one weak binding site (-COOH) to mercury results in $c a$. 2-order-of-magnitude increase on the apparent rate constant under similar experimental conditions. It was found that the rate constant generated by cysteine was almost 1 order of magnitude slower than serine where one hydroxyl group (-OH) was replaced with one-SH group in cysteine (Zheng and Hintelmann, 2010). Our results highlighted the importance of weak binding sites (e.g. - $\mathrm{COOH}$ ) on DOM to $\mathrm{Hg}$ in the photoreduction of $\mathrm{Hg}^{2+}$ to $\mathrm{Hg}^{0}$. 
This document is the unedited Author's version of a Submitted Work that was subsequently accepted for publication in 'Environmental Science \& Technology', copyright @ American Chemical Society after peer review. To access the final edited and published work: https://www.sciencedirect.com/science/article/pii/S0045653514008728

\subsubsection{Branching ratio}

The results obtained by UV-vis spectrophotometry and by TEM- EDS implied that two pathways could occur during the photochemical reaction of $\mathrm{Hg}^{2+}$ with TGA. One was the photoreduction of $\mathrm{Hg}^{2+}$ to $\mathrm{Hg}^{0}$ with the rate constant of $k_{1}$, the other was the photodecomposition of $\mathrm{Hg}^{2+}-\mathrm{TGA}$ complex to $\mathrm{HgS}$ with the rate constant of $k_{2}$. These two parallel reaction pathways could be expressed as follows.

$$
\begin{aligned}
& \text { Pathway } 1: \mathrm{Hg}\left(\mathrm{OOCCH}_{2} \mathrm{~S}\right) \rightarrow \rightarrow \mathrm{Hg}^{0}+\text { products } \\
& \text { Pathway } 2: \mathrm{Hg}\left(\mathrm{OOCCH}_{2} \mathrm{~S}\right) \rightarrow \rightarrow \mathrm{HgS}+\text { products }
\end{aligned}
$$

It was observed that after photolysis of $\mathrm{Hg}(\mathrm{OOCCH} \mathrm{S})$ for $72 \mathrm{~h}$ at $\mathrm{Hg} / \mathrm{TGA}$ molar ratio of 10 , the final $\mathrm{UV}$-vis spectrum after filtration showed absorption peaks at 236, 215, and $204 \mathrm{~nm}$ (Fig. A3). The obtained spectrum agreed well with the previously reported spectrum of $\mathrm{Hg}^{2+}$ (van Loon et al., 2000). The yield of $\mathrm{Hg}^{2+}$ depended linearly on $\left[\mathrm{Hg}\left(\mathrm{OOCCH}_{2} \mathrm{~S}\right)\right]_{0}$. We discovered that $(89 \pm 3) \%$ of the
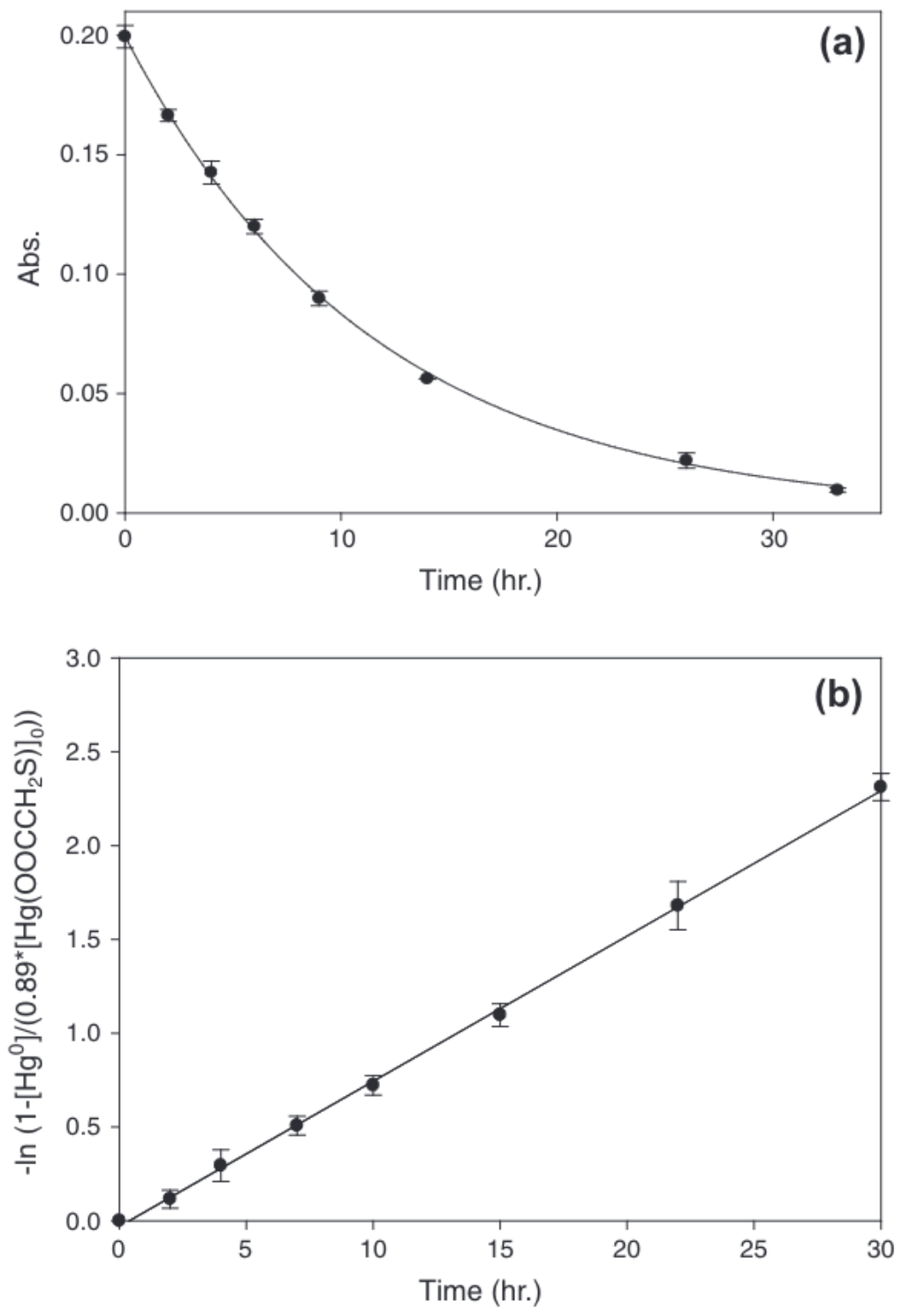

Fig. 2. Kinetic plots of photolysis of the Hg-TGA system obtained by (a) UV-vis spectrophotometry at $\left[\mathrm{Hg}\left(\mathrm{OOCCH}_{2} \mathrm{~S}\right)\right]_{0}=3.5 \times 10^{-5} \mathrm{M}$ and (b) CVAFS at $\left[\mathrm{Hg}\left(\mathrm{OOCCH}_{2} \mathrm{~S}\right)\right]_{0}=2.5 \times 10^{-11} \mathrm{M}$. Error bars are $\pm 2 \sigma$. 
This document is the unedited Author's version of a Submitted Work that was subsequently accepted for publication in 'Environmental Science \& Technology', copyright @ American Chemical Society after peer review. To access the final edited and published work: https://www.sciencedirect.com/science/article/pii/S0045653514008728

reactant undergo photochemical reaction to form elemental mercury at $T=296 \pm 2 \mathrm{~K}, \mathrm{pH} 4.0$.

\subsubsection{CVAFS results}

The generation of elemental mercury $\left(\mathrm{Hg}^{0}\right)$ during the photo- chemical reaction was also confirmed by cold vapour atomic

\section{Table 1}

Apparent rate constants for the photochemical reaction of mercuric ion with thioglycolic acid at $T=296 \pm 2 \mathrm{~K}$ and $\mathrm{pH} 4.0$.

\begin{tabular}{lll}
\hline $\begin{array}{l}\text { Initial concentration of } \\
\text { reactant }(\mathrm{M})\end{array}$ & $\begin{array}{l}\text { Ionic strength } \\
(\mathrm{M})\end{array}$ & $\begin{array}{l}\text { Reaction rate constant, } k \\
\left(10^{5} \mathrm{~s}^{-1}\right)\end{array}$ \\
\hline $2.5 \times 10^{-11}$ & 0.02 & $(2.2 \pm 0.4)^{\mathrm{a}}$ \\
$1.2 \times 10^{-10}$ & 0.02 & $(2.1 \pm 0.4)^{\mathrm{a}}$ \\
$2.5 \times 10^{-10}$ & 0.02 & $(2.3 \pm 0.3)^{\mathrm{a}}$ \\
$3.6 \times 10^{-10}$ & 0.02 & $(2.0 \pm 0.2)^{\mathrm{a}}$ \\
$1.6 \times 10^{-5}$ & 0.02 & $(2.5 \pm 0.5)$ \\
$3.5 \times 10^{-5}$ & 0.02 & $(2.4 \pm 0.4)$ \\
$3.5 \times 10^{-5}$ & 0.001 & $(2.4 \pm 0.1)$ \\
$3.5 \times 10^{-5}$ & 0.1 & $(2.1 \pm 0.4)$ \\
$4.3 \times 10^{-5}$ & 0.02 & $(2.3 \pm 0.3)$ \\
\hline
\end{tabular}

a Apparent rate constants determined by CVAFS.

fluorescent spectrometry (CVAFS). It was found that $\mathrm{Hg}^{0}$ signals increased as a function of the irradiation time and thus the increased formation of elemental mercury. The overall apparent rate constant, $k$, was determined to be $(2.2 \pm 0.4) \times 10^{-5} \mathrm{~s}^{-1}$ at $T=296 \pm$ $2 \mathrm{~K}, \mathrm{pH} 4.0$ by fitting the kinetic data obtained by CVAFS into Eq. (1) (Fig. 2(b)). This value agreed well with our independently calculated value using UV-vis spectrophotometry, which was $(2.4 \pm 0.4) \times 10^{-5} \mathrm{~s}^{-1}$.

\subsection{Effects of $\mathrm{K}^{+}$and $\mathrm{pH}$}

It was observed that when potassium ions were present in reaction mixtures $(I=0.02 \mathrm{M})$, the apparent rate constant increased $\sim 2.6$ times to $(6.2 \pm 0.6) \times 10^{-5} \mathrm{~s}^{-1}$. There is limited knowledge on the effect of cations on mercury photochemistry available in the literature. Since $\mathrm{K}^{+}$has the same charge as $\mathrm{Na}^{+}$, the accelerating effect of $\mathrm{K}^{+}$may be less likely caused by kinetic salt effect (Atkins and de Paula, 2006). A possible mechanism could be the selective molecular recognition of the lattice channel of heterogeneous catalysts (e.g. $\mathrm{HgS}$ ) because $\mathrm{K}^{+}$has a larger ionic radius than $\mathrm{Na}^{+}$(Somorjai and Park, 2008; Miessler and Tarr, 2011). Systematic mechanistic studies on the effect of alkali metals on the reaction rate are needed to confirm this hypothesis.

The $\mathrm{pH}$-dependence of UV-vis spectra was investigated by spectrophotometric titration for $\mathrm{pH} 2-12$ at $I=0.1 \mathrm{M}$ (Fig. A4). It was observed that at $\mathrm{pH}$ above 10 the absorbance of the complex (Complex II) at $235 \mathrm{~nm}$ is negligible. As shown in Fig. A2, the molar absorptivity of the complex at low pH values (Complex I) was $4 \times 10^{3} \mathrm{M}^{-1} \mathrm{~cm}^{-1}$ at $235 \mathrm{~nm}$. Using the previous method for studying the $\mathrm{pH}$-dependence of the UV spectrum of $\mathrm{Hg}^{2+}$-sulfite complexes (van Loon et al., 2001), the curve in Fig. A4 was reproduced by fitting the data to Eq. (6):

$$
A=\left[H g^{2+}-T G A\right]_{t o t a l} \cdot\left(\frac{\varepsilon \cdot\left[H^{+}\right]}{\left[H^{+}\right]+K}\right)
$$

where $A,\left[\mathrm{Hg}^{2+}-\mathrm{TGA}\right]_{\text {total }}$ and $\varepsilon$ represented the absorbance at $235 \mathrm{~nm}$, the total concentration of the $\mathrm{Hg}^{2+}-\mathrm{TGA}^{2}$ complexes and the molar absorptivity of complex I at $235 \mathrm{~nm}$, respectively. $K$ was assigned to the equilibrium between complexes I and II. Speciation calculation was performed for $\mathrm{pH} 2-6$ considering the complexation of $\mathrm{Hg}^{2+}$ with TGA and deprotonation of either - $\mathrm{SH}$ or - $\mathrm{COOH}$ on TGA and it was found that the major species was $\mathrm{Hg}\left(\mathrm{OOCCH}_{2} \mathrm{~S}\right)$. Therefore, the protonated form in acidic solution, complex I, corresponded to $\mathrm{Hg}\left(\mathrm{OOCCH}_{2} \mathrm{~S}\right)$. Its deprotonation in alkaline solution may involve a coordinated water molecule, Eq. (7):

$$
\underset{\text { complex I }}{\mathrm{Hg}\left(\mathrm{OOCCH}_{2}\right)\left(\mathrm{H}_{2} \mathrm{O}\right)_{n}} \leftrightarrow \underset{\text { complex II }}{\mathrm{Hg}\left(\mathrm{OOCCH}_{2}\right)\left(\mathrm{H}_{2} \mathrm{O}\right)_{n-1}(\mathrm{OH})^{-}+H^{+}}
$$

\section{Conclusion}

We herein performed the first study on the photochemical reaction of oxidized mercury species with thioglycolic acid, an important 
This document is the unedited Author's version of a Submitted Work that was subsequently accepted for publication in 'Environmental Science \& Technology', copyright @ American Chemical Society after peer review. To access the final edited and published work: https://www.sciencedirect.com/science/article/pii/S0045653514008728

thiol in aquatic environment. When $\mathrm{Hg}^{2+} / \mathrm{TGA}$ molar ratio was higher than 1 at acidic $\mathrm{pHs}$, aqueous TGA reacted with mercuric ion to form $\mathrm{Hg}\left(\mathrm{OOCCH}_{2} \mathrm{~S}\right)$ complex, whose $\mathrm{UV}$-vis spectrum showed two absorption shoulders at ca. $195 \mathrm{~nm}$ and $235 \mathrm{~nm}$. Photolysis of the reaction mixture resulted in the formation of both elemental mercury (Pathway 1) and $\mathrm{HgS}$ particles (Pathway 2). The existence of $\mathrm{HgS}_{(\mathrm{s})}$ in the reaction system indicated the possible occurrence of hetexogeneous reactions. The role of $\mathrm{HgS}$ particles played in heterogeneous reactions of $\mathrm{Hg}$ needs to be assessed and could provide important information on assessing and remediating mercury hot- spots in the environment. The product branching fractionation of Pathway 1 was $(89 \pm 3) \%$. The apparent rate constant was obtained by monitoring the loss of $\mathrm{Hg}\left(\mathrm{OOCCH}_{2} \mathrm{~S}\right)$ using $\mathrm{UV}$-vis spectrophotometry as well as by following the generation of $\mathrm{Hg}^{0}$ by CVAFS. Under our experimental conditions, the photochemical reaction between $\mathrm{Hg}$ and TGA was apparently first-order with the rate constant of $(2.3 \pm 0.4) 10^{-5} \mathrm{~s}^{-1}$ at $T=296 \pm 2 \mathrm{~K}, \mathrm{pH}$ 4.0. The change of UV-vis spectra of the reaction mixture with $\mathrm{pH}$ was significant; hence the efficiency of photolysis of $\mathrm{Hg}$ - TGA complexes may vary in natural waters with different $\mathrm{pHs}$ and should be studied further. Our findings may be relevant at acidic aquatic environment contaminated with mercury. Future work on the detailed photochemistry of $\mathrm{Hg}^{2+}$ complexed with 2 thiol groups are desirable. Low molecular mass thiols are produced mainly under low redox conditions (e.g. bottom waters) where UV radiation is less important as compared to surface waters. Furthermore natural organic matter (NOM) comprising thiol groups are present in virtu- ally all natural waters, which will complicate the picture. Whether $\mathrm{HgS}$ (s) could form by UV in such a system needs further evaluation.

\section{Acknowledgements}

We would like to cordially thank two anonymous reviewers for their constructive comments and suggestions. We thank all the past and present members of Prof. Ariya's research group for their valuable advice and Ms. Cavaliere for proofreading the manuscript. We are grateful for continuous financial support from Natural Sciences and Engineering Research Council of Canada (NSERC), Le Fonds québecois de la recherche sur la nature et les technologies (FQRNT), CARA project, Environment Canada and Canadian Foundation for Innovation (CFI).

\section{Appendix A. Supplementary material}

Supplementary data associated with this article can be found, in the online version, at http://dx.doi.org/10.1016/j.chemosphere. 2014.07.022.

\section{References}

Al-Farawati, R., van den Berg, C.M.G., 2001. Thiols in coastal waters of the Western North Sea and English channel. Environ. Sci. Technol. 35, $1902-1911$.

Atkins, P., de Paula, J., 2006. Physical Chemistry for the Life Sciences. Freeman and Company, New York, WH.

Barnett, M.O., Harris, L.A., Turner, R.R., Stevenson, R.J., Henson, T.J., Melton, R.C., Hoffman, D.P., 1998. Formation of mercuric sulfide in soil. Environ. Sci. Technol. 31, $3037-3043$.

Baughman, G.L., Gordon, J.A., Wolfe, N.L., Zepp, R.G., 1973. Chemistry of organomercurials in aquatic systems. EPA-660/3-73-012, U.S. Environmental Protection Agency.

Deonarine, A., Hsu-Kim, H., 2009. Precipitation of mercuric sulfide nanoparticles in NOM-containing water: implications for the natural environment. Environ. Sci. Technol. 43, 2368-2373.

Dong, W., Bian, Y., Liang, L., Gu, B., 2011. Binding constants of mercury and dissolved organic matter determined by a modified ion exchange technique. Environ. Sci. Technol. 45, 3576-3583.

Dryden, C.L., Gordon, A.S., Donat, J.R., 2007. Seasonal survey of copper-complexing ligands and thiol compounds in a heavily utilized, urban estuary: Elizabeth River, Virginia. Mar. Chem. 103, 276-288.

Feng, X.B., Lu, J.Y., Gregoire, D.C., Hao, Y.J., Banic, C.M., Schroeder, W.H., 2004. Analysis of inorganic mercury species associated with airborne particulate matter/aerosols: method development. Anal. Bioanal. Chem. 380, 683-689.

Gardfeldt, K., Jonsson, M., 2003. Is bimolecular reduction of $\mathrm{Hg}$ (II) complexes possible in aqueous systems of environmental importance. J. Phys. Chem. A 107, 44784482.

Huerta-Diaz, M.A., Morse, J.W., 1992. Pyritization of trace metals in anoxic marine sediments. Geochim. Cosmochim. Acta 56, $2681-2702$.

Hyland, M.M., Jean, G.E., Bancroft, G.M., 1990. XPS and AES studies of Hg(II) sorption and desorption reactions on sulphide minerals. Geochim. Cosmochim. Acta 54, $1957-1967$.

Jalilehvand, F., Leung, B.O., Izadifard, M., Damian, E., 2006. Mercury(II) cysteine complexes in alkaline aqueous solution. Inorg. Chem. 45, 66-73.

Karamchandani, P., Zhang, Y., Chen, S.-Y., Balmori-Bronson, R., 2012. Development of an extended chemical mechanism for global-through-urban applications. Atmos. Pollut. Res. 3, 1-24.

Krezel, A., Bal, W., 1999. Coordination chemistry of glutathione. Acta Biochim.Polinica 46, 567-580.

Kunkely, H., Horvath, O., Vogler, A., 1997. Photophysics and photochemistry of mercury complexes. Coord. Chem. Rev. $159,85-93$.

Lanzillotta, E., Ferrara, R.,2001. Daily trend of dissolved gaseous mercury concentration in coastal seawater of the Mediterranean basin. Chemosphere 45, 935 940.

Leung, B.O., Jalilehvand, F., Mah, V., 2007. Mercury(II) penicillamine complex formation in alkaline aqueous solution. Dalton Trans., 4666-4674.

Lowry, G.V., Shaw, S., Kim, C.S., Rytuba, J.J., Brown, G.E., 2004. Macroscopic and microscopic observations of particle-facilitated mercury transport from new idria and sulphur bank mercury mine tailings. Environ. Sci. Technol. 38, 5101-5111.

Mah, V., Jalilehvand, F., 2008. Mercury(II) complex formation with glutathione in alkaline aqueous solution. J. Biol. Inorg. Chem. $13,541-553$.

Martell, A.E., Smith, R.M., Motekaitis, R.J., 1998. NIST critically selected stability constants of metal complexes data base. NIST Std. Ref. Database \# 46. Department of Commerce, Gaithersburg, MD.

Matrai, P.A., Vetter, R.D., 1988. Particulate thiols in coastal waters: the effect of light and nutrients on their planktonic production. Limnol. Oceanogr. 33, 624-631 Miessler, G.L., Tarr, D.A., 2011. Inorganic Chemistry, fourth ed. Pearson Prentice Hall, Upper Saddle River, NJ. c2011.

Munthe, J., Wangberg, I., Pirrone, N., Iverfeldt, A., Ferrara, R., Ebinghaus, R., Feng, X., Gardfeldt, K.G.K., Lanzillotta, E., Lindberg, S.E., Lu, J., Mamane, Y., Prestbo, E., Schmolke, S., Schroeder, W.H., Sommar, J., Sprovieri, F., Stevens, R.K., Stratton, W., Tuncel, G.A.U., 2001. Intercomparison of methods for sampling and analysis of atmospheric mercury species. Atmos. Environ. 35, 3007-3017.

Nriagu, J.O., 1994. Mechanistic steps in the photoreduction of mercury in natural waters. Sci. Total Environ. 154, 1-8. 
This document is the unedited Author's version of a Submitted Work that was subsequently accepted for publication in 'Environmental Science \& Technology', copyright $\odot$ American Chemical Society after peer review. To access the final edited and published work: https://www.sciencedirect.com/science/article/pii/S0045653514008728

O’Driscoll, N.J., Siciliano, S.D., Lean, D.R.S., 2003. Continuous analysis of dissolved gaseous mercury in freshwater lakes. Sci. Total Environ. $304,285-294$.

Pal, B., Ikeda, S., Ohtani, B., 2003. Photoinduced chemical reactions on natural single crystals and synthesized crystallites of mercury(II) sulfide in aqueous solution containing naturally occurring amino acids. Inorg. Chem. 42, 1518-1524.

Ravichandran, M., Aiken, G.R., Ryan, J.N., Reddy, M.M., 1999. Inhibition of precipitation and aggregation of metacinnabar (mercuric sulfide) by dissolved organic matter isolated from the Floride everglades. Environ. Sci. Technol. 33, 1418-1423.

Rivichandran, M., 2004. Interactions between mercury and dissolved organic matter-a review. Chemosphere 55, 319-331.

Rivichandran, M., Aiken, G.R., Reddy, M.M., Ryan, J.N., 1998. Enhanced dissolution of cinnabar (mercuric sulfide) by dissolved organic matter isolated from the Florida everglades. Environ. Sci. Technol. 32, 3305-3311.

Si, L., Ariya, P.A., 2008. Reduction of oxidized mercury species by dicarboxylic acids (C2-C4): kinetic and product studies. Environ. Sci. Technol. 42, $5150-5155$.

$\mathrm{Si}$, L., Ariya, P.A., 2011. Aqueous photoreduction of oxidized mercury species by selected alkanethiols. Chemosphere 84, 1079-1084.

Skyllberg, U., Xia, K., Bloom, P.R., Nater, E.A., Bleam, W.F., 2000. Binding of mercury(II) to reduced sulfur in soil organic matter along upland-peat soil transects. J. Environ. Qual. 29, 855-865.

Smith, D.S., Bella, R.A., Kramerb, J.R., 2002. Metal speciation in natural waters with emphasis on reduced sulfur groups as strong metal binding sites. Comp. Biochem. Physiol. C 133, 65-74.

Somorjai, G.A., Park, J.Y., 2008. Molecular factors of catalytic selectivity. Angew.Chem. Int. Ed. 47, 9212-9228.

Subir, M., Ariya, P.A., Dastoor, A.P., 2011. A review of uncertainties in atmospheric modeling of mercury chemistry I. Uncertainties in existing kinetic parameters fundamental limitations and the importance of heterogeneous chemistry. Atmos. Environ. 45, 5664-5676.

Tang, D., Hung, C.-C., Warnken, K.W., Santschit, P.H., 2000. The distribution of biogenic thiols in surface waters of Galveston Bay. Limnol. Oceanogr. 45, 12891297.

van Loon, L., Mader, E., Scott, S.L., 2000. Reduction of the aqueous mercuric ion by sulfite: UV spectrum of $\mathrm{HgSO}_{3}$ and its intramolecular redox reaction. J. Phys. Chem. A 104, 1621-1626.

van Loon, L., Mader, E., Scott, S.L., 2001. Sulfite stabilization and reduction of the aqueous mercuric ion: kinetic determination of sequential formation constants. J. Phys. Chem. A 105, 3190-3195.

Zhang, H., Lindberg, S.E., 2001. Sunlight and iron(III)-induced photochemical production of dissolved gaseous mercury in freshwater. Environ. Sci. Technol. 35, 928-935.

Zhang, J., Wang, F., House, J.D., Page, B., 2004. Thiols in wetland interstitial waters and their role in mercury and methylmercury speciation. Limnol. Oceanogr. 49, 2276-2286.

Zhang, T., Kim, B., Levard, C., Reinsch, B.C., Lowry, G.V., Deshusses, M.A., Hsu-Kim, H., 2012. Methylation of mercury by bacteria exposed to dissolved, nanoparticulate and microparticulate mercuric sulfides. Environ. Sci. Technol. 46, 6950-6958.

Zheng, W., Hintelmann, H., 2010. Isotope fractionation of mercury during its photochemical reduction by low-molecular-weight organic compounds. J. Phys. Chem. A 114, 4246-4253. 